\title{
Efficacy of Allogeneic Hematopoietic Stem Cell Transplantation in Relapse/Refractory B-ALL Patients After Chimeric Antigen Receptor T Cell Therapy: A Systematic Review and Meta-analysis
}

Linyan Tian

Tianjin Medical University Cancer Institute and Hospital, National Clinical Research Center for Cancer, Tianjin's Clinical Research Center for Cancer

Jinhuan Wang

Second Hospital of Tianjin Medical University

Yixin Zhai

Tianjin Medical University Cancer Institute and Hospital, National Clinical Research Center for Cancer, Tianjin's Clinical Research Center for Cancer

Su Liu

Tianjin Medical University Cancer Institute and Hospital, National Clinical Research Center for Cancer, Tianjin's Clinical Research Center for Cancer

Yanan Jiang

Tianjin Medical University Cancer Institute and Hospital, National Clinical Research Center for Cancer, Tianjin's Clinical Research Center for Cancer Wenqi Wu

Tianjin Medical University Cancer Institute and Hospital, National Clinical Research Center for Cancer, Tianjin's Clinical Research Center for Cancer

Yangyang Lv

Tianjin Medical University Cancer Institute and Hospital, National Clinical Research Center for Cancer, Tianjin's Clinical Research Center for Cancer

\section{Donghui Xing}

Tianjin Medical University Cancer Institute and Hospital, National Clinical Research Center for Cancer, Tianjin's Clinical Research Center for Cancer

\section{Hong Xu}

Tianjin Medical University Cancer Institute and Hospital, National Clinical Research Center for Cancer, Tianjin's Clinical Research Center for Cancer Huimeng Sun

Tianjin Medical University Cancer Institute and Hospital, National Clinical Research Center for Cancer, Tianjin's Clinical Research Center for Cancer Yafei Wang

Tianjin Medical University Cancer Institute and Hospital, National Clinical Research Center for Cancer, Tianjin's Clinical Research Center for Cancer Zhigang Zhao ( $\nabla$ zzhao01@tmu.edu.cn)

Tianjin Medical University Cancer Institute and Hospital, National Clinical Research Center for Cancer, Tianjin's Clinical Research Center for Cancer

\section{Research Article}

Keywords: R/R B-ALL, CAR-T cell therapy, Allo-HSCT, Survival, Meta-analysis

Posted Date: July 22nd, 2021

DOI: https://doi.org/10.21203/rs.3.rs-677636/v1

License: @ (i) This work is licensed under a Creative Commons Attribution 4.0 International License. Read Full License 


\section{Abstract}

Background: Allogeneic hematopoietic stem cell transplantation(allo-HSCT) consolidation therapy after chimeric antigen receptor(CAR) T cell therapy has emerged as an alternative in patients with B-ALL in the past decade. However, the efficiency remains unclear. In this study, we aimed to systematically analysis the effect of allo-HSCT for Relapse/Refractory(R/R) B-ALL patients after CAR-T cell therapy on survival and relapse rate(RR).

Methods: We searched potential documents up to Jan.31st, 2021 in PUBMED, EMBASE, Cochrane Library and Springer and analyzed them by Cochrane Collaboration RevMan 5.3 software.

Results: Allo-HSCT was efficient in improving short(6-month) and long(1-year and 2-year) term overall survival(OS) and leukemia-free survival(LFS). Transplantation could also reduce RR of R/R B-ALL regardless of patients' characteristics and time of allo-HSCT. Besides, CAR-T cell products with 4-1BB domain bridging allo-HSCT were associated with a better survival. Subgroup analysis indicated allo-HSCT was more likely to exert a noticeable influence on survival of junior individuals $(\leq 40)$ and Asian groups. A suitable period between allo-HSCT and CAR-T cell therapy( $\leq 70$ days) would make a difference. Interestingly, some features of patients, such as a HSCT history or BCR-ABL1 rearrangement (Philadelphia chromosome, Ph) may have an effect on the efficacy of allo-HSCT.

Conclusion: Allo-HSCT consolidation therapy after CAR-T cell therapy induced a promising short-and-long term survival of R/R B-ALL patients. Senior patients, prior HSCT history and BCR-ABL1 rearrangement $(\mathrm{Ph})$ might be poor prognostic factors. Further studies are needed to explore the optimal time for allo-HSCT.

\section{Background}

Acute B-cell lymphoblastic leukemia (B-ALL), tending to disturb the young, is regarded as the most common cancer in pediatric patients[1, 2].Although different new agents come out, combination chemotherapy with vincristine, corticosteroids and anthracycline[3] serves as the backbone of treatment in BALL patients, however, around $15-20 \%$ adults eventually suffer from an inevitable relapse[4, 5].As for R/R B-ALL patients, consolidative allo-HSCT is more likely to be an option after high dose chemotherapy or a salvage regimen after relapse[6].

In recent years, the booming of CAR-T cell therapy has given hope to patients with R/R B-ALL with a complete remission(CR) of 70-90\%[2, 7, 8]. CAR-T cell therapy induces high initial remission rates but no evidence indicates it can improve disease free survival(DFS) and $40-50 \%$ patients usually relapse within one year $[9,10]$. Patients who achieve CR after CAR-T cell therapy often come across a dilemma when some of them are advised to undergo transplantation. In light of published clinical trials, allo-HSCT consolidation has been used in R/R B-ALL patients after CAR-T cell therapy and performed a favorable prognosis concerning efficiency and safety[11]. However, whether allo-HSCT consolidation is associated with a more durable remission and a better survival remains equivocal[12, 13].

As there is no solid evidence over merits of consolidative allo-HSCT, we summarized clinical data to identify the role of allo-HSCT after CAR-T cell therapy. This review intended to explore the impact of allo-HSCT on short and long term survival as well as RR for R/R B-ALL patients after CAR-T. Moreover, we will discuss some factors which may affect the efficacy of allo-HSCT post CAR-T cell therapy.

\section{Methods}

\subsection{Literature Search}

We carried out the study in compliance with the standards set by the Preferred Reporting Items for Systematic Reviews and Meta-Analysis statement. Eligible studies with the latest update on Jan.30,2021 were searched in Pubmed, EMBASE, Cochrane Library and Springer. Only English and Chinese publications are included. We combined Medical Subject Heading (MeSH) terms and free-text terms concerning "CAR-T" and "B-ALL" to access potential studies. Meanwhile, relevant articles in the reference are also included.

\subsection{Inclusion and exclusion criteria}

The studies were included if they met the following criteria:(1)studies must have two arms of R/R B-ALL patients in which one arm used allo-HSCT whereas the other didn't use allo-HSCT after CAR-T;(2)studies must have reported at least one of the three outcomes in both arms: OS, LFS and RR;(3)patients with CR after CAR-T cell therapy were bridged to allo-HSCT or not.(4)sufficient data was provided in abstract although the full text was not available.

The exclusion criteria were (1) reviews, viewpoints, perspectives or correspondences; (2) lack of effective data of outcome as described above for two arms; (3) basic research or animal studies;(4) duplicated publications.

\subsection{Study Qualitative Assessment}

We adopt the Methodological Index for Non-randomized Studies(MINORS) to assess the quality of the inclusive studies[14]. As all studies involved are nonrandomized studies, MINORS is a scoring tool for evaluation of both internal and external validity.

\subsection{Data Extraction}

Two authors independently collected and extracted the following information: first author, publication year, number of patients in different groups, details of treatments (costimulatory domain, days between CAR-T cell therapy and allo-HSCT, dose of CAR-T cells), patient characteristics (age, ethnicity, rate of prior- 
HSCT patients, patients with BCR-ABL1 rearrangement (Ph), patients with complex karyotype) and survival outcomes (OS, LFS and RR). Disputes were settled by a third reviewer or through discussion.

\subsection{Statistical analysis}

We use the Cochrane Collaboration RevMan 5.3 software (The Cochrane Collaboration, London, United Kingdom) to analysis therapeutic efficacy. In addition, the $R$ statistic was used to test for heterogeneity. A fixed-effect model was applied to calculate pooled effects when $R \llbracket 50 \%$. Otherwise, we use the randomeffect model. In order to explore the source of heterogeneity, we performed subgroup analysis by middle time interval between CAR-T cell therapy and allo$\mathrm{HSCT}(\leq 70$ days vs $₫ 70$ days), the proportion of patients with a HSCT history $(\leq 20 \%$ vs $₫ 20 \%)$ and the rate of $\mathrm{BCR}-\mathrm{ABL} 1$ rearrangement(Ph) patients $(\leq 30 \%$ vs $₫ 30 \%) . P$ values $₫ 0.05$ were considered statistically significant. Sensitivity analysis was conducted to estimate the effect with removal of the largest sample size among all studies.

\section{Results}

\subsection{Literature Search Results and Study characteristics}

The flowchart shown in Fig 1 illustrated our search process. 774 results were accessible in different databases, of which 393 duplicates were excluded. Meanwhile, another 8 records available in the reference were regarded as relevant reports. In terms of the exclusion criteria above, 16 studies, involving 690 patients, were included ultimately[15-30]. Three studies which had sufficient data in abstract despite no available full text were also included.

Table 1 depicts the characteristics of the inclusive studies. All studies were two-arm clinical trials on $690 \mathrm{R} / \mathrm{R}$ B-ALL patients in total published from 2015 to 2021. The sample sizes ranged from 9 to 122 . The patients' age varied across studies. The CAR-T dose ranged from $0.1 \times 10^{\wedge} 6$ to $500 \times 10^{\wedge} 6 \otimes T a b l e ~ S 1 \rrbracket a n d$ the median days between CAR-T cell therapy and allo-HSCT were 44-104 days. The costimulatory domain was either CD28 or 4-1BB. In respect of obtainable data, the proportion of patients with prior HSCT, BCR-ABL1 rearrangement (Ph) and complex karyotype was 0-40\%, 2.1-100\% and 4.9-50\%,respectively. More details were shown in Table S1.

Data for OS were available in 12 studies with 558 patients[15-19, 21-24, 28-30], 8 studies of which with 446 patients in total provided data of LFS or EFS[15$17,19,22,24,29,30]$. Event was defined as no treatment failure, relapse or death. Fortunately, all objectives in the five studies reporting EFS achieved CR or CR with incomplete hematologic recovery(CRi) after CAR-T cell therapy[16, 19, 22, 29, 30]. Due to the fact that no "relapse" event occurred, the data of EFS and LFS could be merged and analyzed as LFS. With regard to the other two studies, DFS data were available rather than LFS or EFS[18, 21]. As difference existed between the definition of DFS and LFS, it was not proper to merge them all.

\subsection{Study Quality}

The quality of each study was assessed by the Methodological Index for Non-randomized Studies (MINORS). The detailed scores are listed in Table S2. Generally, the overall quality was adequate.

\subsection{Association of allo-HSCT after CAR-T cell therapy with short or long term OS}

10 studies with 512 patients reported 6-month OS[15-19, 22-24, 28, 29]. 10 studies with 485 patients reported 1-year OS[15-19, 21-24, 29]. 6 studies with 324 patients reported 2-year OS[15, 19, 22, 24, 29, 30]. As demonstrated in Fig 2, those who chose HSCT regimen after CAR-T cell therapy got a significantly better OS of both short and long term(6-month OS: odds ratio(OR) $=0.34 ; 95 \%$ confidence interval $(\mathrm{Cl})=0.19-0.61 ; \mathrm{P}=0.0003 ; 1$-year $0 \mathrm{~S}$ : OR $=0.24 ; 95 \% \mathrm{Cl}=0.15-$ $0.38 ; \mathrm{P}<0.00001 ; 2$-year OS: OR=0.26; $95 \% \mathrm{Cl}=0.16-0.43 ; \mathrm{P}<0.00001)$. Since there was low heterogeneity between these studies, a fixed-effect model was applied.

Subgroup analysis $\varangle$ Fig $3 \otimes$ based on general characteristics acquired of patients such as median age, ethnicity and costimulatory domain illustrated alloHSCT exerted a noticeable influence on survival of junior individuals $(\leq 40)(P<0.00001)$ and Asian groups $(P<0.00001)$. Little promotion of survival was caught in senior individuals $(\mathbb{4} 40)(\mathrm{P}=0.1)$ and Caucasian groups $(\mathrm{P}=0.11)$. Moreover, CAR-T with $4-1 \mathrm{BB}$ rather than $\mathrm{CD} 28$ bridging allo-HSCT brought about a better survival.

Intensive study was carried out as follows in Fig 4. Subgroup analysis of 1-year OS by period between CAR-T cell therapy and allo-HSCT showed HSCT was observed to exert a marked influence on patients who received HSCT less than 70 days $(\mathrm{P}<0.00001)$ whereas no obvious effect on those who received HSCT more than 70 days $(P=0.31)$. Furthermore, allo-HSCT brought an improvement in OS in subgroups with the proportion of prior HSCT $\leq 20 \%(P<$ 0.00001). However, no apparent improvement was observed in the other group $(P=0.07)$. Regarding the rate of $B C R-A B L 1$ rearrangement $(P h)$ patients $(\leq 30 \%$ and $₫ 30 \%)$, allo-HSCT after CAR-T cell therapy did not seem to be beneficial for survival in the subgroup with more high-risk subtype patients( $\mathrm{P}=0.28)$. But allo-HSCT were observed to be efficacious in " $\leq 30 \%$ "group $(\mathrm{P}<0.00001)$.

\subsection{Association of allo-HSCT after CAR-T cell therapy with short or long term LFS}

6 studies with 307 patients reported 6-month LFS[15, 17, 19, 22, 24, 29]. 7 studies with 409 patients reported 1-year LFS[15-17, 19, 22, 24, 29]. 6 studies with 324 patients reported 2-year LFS[15, 19, 22, 24, 29, 30]. As demonstrated in Fig 5, those who chose allo-HSCT regimen after CAR-T cell therapy got a significantly better short-and-long-term LFS. (6-month LFS: OR = 0.13; 95\% Cl=0.05-0.29; P<0.00001; 1-year LFS: OR =0.19; 95\% Cl = 0.09-0.41; P< 0.0001; 2-year LFS: OR= $0.26 ; 95 \% \mathrm{Cl}=0.16-0.43 ; \mathrm{P}<0.00001)$. A fixed-effect model was applied to analysis data of 6-month LFS and 2-year LFS while a randomeffect one was applied to analysis data of 1 -year LFS as $R=55 \%$. 
After the removal of one article[16], $P$ got down to $18 \%$. And the removal of other articles respectively didn't lead to a decrease of $R$. So the study of Zhang et al. was considered to be the source of heterogeneity. As indicated in Table S1, the proportion of patients with a complex karyotype(47.4\%) was dominantly larger than that in other studies with available data. So we conjectured chromosome abnormalities might affect the efficiency of post-HSCT therapy.

Subgroup analysis(Fig 6) similar to that of 1-year OS presented that there were associations between allo-HSCT and 1-year LFS in younger groups(age $\leq 40 \mathbb{Z}$ $P<0.00001)$ instead of older ones(age $\triangle 40 \otimes P=0.34)$ and Asian $\varangle P<0.00001$ rather than Caucasian $(p=0.15)$. As the lack of accurate data in studies concerning 1-year LFS, we conducted subgroup analysis about the relationship between costimulatory domain and 2-year LFS. CAR-T with 4-1BB ( $P<$ $0.00001)$ rather than $\mathrm{CD} 28(\mathrm{P}=0.15)$ bridging allo-HSCT improved the long-term prognosis.

In a deep analysis(Fig 7), HSCT played a significant role in improving 1-year LFS in subgroups of "period between CAR-T cell therapy and allo-HSCT no more than 70 days" $(P<0.00001)$, "the proportion of prior HSCT $\leq 20 \%$ " $(P<0.00001)$ and "the proportion of BCR-ABL1 rearrangement $(P h) \leq 30 \%$ " $(P<0.00001)$, yet in the other subgroups, no remarkable difference was observed.

Of note, there was an obvious inter-group difference of prior-HSCT between CART and CART+HSCT groups $(\mathrm{P}<0.001)$, so it was omitted in the second subgroup analysis[15]. As shown in Fig 7 , a moderate heterogeneity existed in one of the second subgroups with the probable reason that only two studies were included with the proportion of patients with BCR-ABL1 rearrangement(Ph) was $100 \%$ for one study and $10 \%$ for the other[22, 24]. Subsequently, we removed the study of Bin Gu in the subgroup analysis as no object in this study had a prior-HSCT regimen therapy, which was more likely considered as an interference.

\subsection{Relapse rate}

We analyzed the potential influence of allo-HSCT in reducing RR. The outcomes were shown in Fig 8, allo-HSCT was promising in reduction of RR( $\left.\right|^{2}=32 \%, P<$ 0.00001).Subgroup analysis above illustrated allo-HSCT after CAR-T cell therapy worked in reducing RR which were not restricted by time of HSCT, a priorHSCT history and BCR-ABL1 rearrangement $(\mathrm{Ph})$.

\subsection{Sensitive analysis and publication bias}

In the sensitivity analysis, after removal of the largest sample size of all the studies included, the pooled OS, LFS and RR didn't change prominently.

Despite few studies involved for assessing publication bias, there was no evident publication bias as visual inspection of the funnel plot (Fig 9). The sources of potential bias were primarily a lack of blind evaluation of endpoints and a calculation of $95 \% \mathrm{Cl}$ in several studies.

\section{Discussion}

Recently, a subset of R/R B-ALL patients who underwent a CAR-T cell therapy gained molecular remissions and later achieved CR in related studies[31]. It is still under discussion if a sequent allo-HSCT should be conducted for a better prognosis. As no randomized controlled trials(RCT) was published, our metaanalysis examined 16 studies involving 690 patients and demonstrated consolidative allo-HSCT could improve both short(6 month) and long( 1 year, 2 year) term survival and decrease RR of R/R B-ALL patients, which supported the conclusion of the only meta-analysis published before[32]. However, it seemed not all R/R B-ALL patients could gain benefit from allo-HSCT after CAR-T cell therapy in our study.

Previous researches made multivariable analysis and represented that age was considered as a factor to impact survival after allo-HSCT therapy[15, 24]. In our study, we set the cut-off value as 40 years old(median age) for a subgroup analysis where allo-HSCT was not observed to work significantly on survival in the senior groups. Besides, they are more susceptible for adverse effect, such as graft-versus-host disease(GVHD) and severe infection[33, 34]. Hence, the senior might be precluded from allo-HSCT consolidation given an inconspicuous improvement on survival, a torturing adverse event and a high cost.

Furthermore, patients with a transplantation history were inclined to have little response to another allo-HSCT and suffer from a high risk of treatmentrelated mortalities even though they were fortunate enough to achieve CR after CAR-T cell therapy[22, 23, 35]. It was revealed that patients didn't show a good response to a second infusion of HSCT from the same donor[36]. In an analysis on behalf of the acute leukemia working Party of European Group for Blood and Marrow Transplantation (EBMT), 93 patients with a HSCT history underwent a second transplantation[37]. Only 6 of them kept alive at last. As for our study, patients with a HSCT history didn't show a considerable improvement on survival after allo-HSCT. So, we inferred those patients were probably suitable for a targeted therapy or other regimen rather than another transplantation as consolidation.

As one of the high-risk cytogenetic features according to AIEOP-BFM ALL 2017 protocol, BCR-ABL1 fusion gene, which results from Ph chromosome translocation reminds a poor prognosis[38]. Those patients are inclined to relapse and hardly response to conventional treatments[39]. In our study, consolidative allo-HSCT barely exerted an influence on survival of patients with BCR-ABL1 rearrangement(Ph). However, in study of Gu et al., HSCT seemed beneficial for survival in patients with BCR-ABL1 rearrangement(Ph), which seems to be contradictory to our results[24]. It is in suspension which factor, "no transplantation history" or "patients with BCR-ABL1 rearrangement(Ph)", was associated to a better survival after HSCT consolidation in their research. Before more solid evidence was found, we reckoned patients with BCR-ABL1 rearrangement (Ph) should prudently choose consolidative allo-HSCT on a caseby-case basis.

Additionally, time to allo-HSCT was more likely related to survival. Present studies illustrated that shorter time from CAR-T therapy to allo-HCT was associated with a lower risk for death and a better overall survival[40, 41]. Here, we made a subgroup analysis aiming to select a suitable therapeutic window. We set the window at 60 or 65 days and no difference between subgroups was found. In our study, allo-HSCT exerted a positive effect on survival as the median time interval shorter than 70 days while no influence was observed in the other subgroup. Therefore we speculated an optional period between the two treatments 
would be around 70 days for a rewarding consolidative therapy. As for other thresholds, however, we failed to make a subgroup analysis due to the limitation of data. More experimental data are warranted to settle a deadline for allo-HSCT after CAR-T cell therapy.

In conclusion, CAR-T-cell bridging allo-HSCT is capable of enhancing short and long term survival and reducing RR in suitable patients with R/R B-ALL. However, no RCT in this field is available up to now. Anyway, we hope this review could arouse more attention of professors in this field to set a standard about authoritative instructions for allo-HSCT in R/R B-ALL patients with CAR-T cell therapy. A rating scale to appraise the necessity of allo-HSCT is supposed to be performed and more details are eager to be refined as more relevant studies emerge.

\section{Declarations}

Ethics approval and consent to participate As this study was based on published data, no ethics approval was sought for the study.

Consent for publication Not applicable.

Availability of data and material All data generated or analysed during this study are included in this published article [and its supplementary information files].

Competing interests The authors declare that they have no conflict of interest.

Funding This research was funded by the National Natural Science Foundation of China (81870150), the National Natural Science Foundation of China(81670102), the Natural Science Foundation of Tianjin(16JCYBJC25200) and the National Natural Science Foundation of China(81572543).

Authors Contributions Z.Z.G and W.Y.F designed the study. T.L.Y, W.J.H, and Z.Y.X made the statistical plan. T.L.Y and W.J.H performed the key analyses. L.S,J.Y.N, W.W.Q and X.D.H collected the data. X.H and S.H.M assisted in data interpretation and quality assessment. T.L.Y wrote the manuscript. W.J.H revised the manuscript. All authors have read and approved the manuscript.

Acknowledgements We acknowledge the Pubmed, EMBASE, Cochrane Library and Springer databases for providing data needed for our analysis. We would also like to express our gratitude to clinical trials on CAR-T cell therapy which are inspirations for our manuscript.

\section{References}

1. Hunger SP, Mullighan CG: Acute Lymphoblastic Leukemia in Children. N Eng/ J Med 2015, 373(16):1541-1552. https://doi.org/10.1200/JC0.2011.37.8018

2. Hucks G, Rheingold SR: The journey to CAR T cell therapy: the pediatric and young adult experience with relapsed or refractory B-ALL. Blood Cancer $J$ 2019, 9(2):10. https://doi.org/10.1038/s41408-018-0164-6

3. Lamanna N, Heffner LT, Kalaycio M, Schiller G, Coutre S, Moore J, Seiter K, Maslak P, Panageas K, Golde D et al: Treatment of adults with acute lymphoblastic leukemia: do the specifics of the regimen matter?: Results from a prospective randomized trial. Cancer 2013, 119(6):1186-1194. https://doi.org/10.1002/cncr.27901

4. Martino M, Alati C, Canale FA, Musuraca G, Martinelli G, Cerchione C: A Review of Clinical Outcomes of CAR T-Cell Therapies for B-Acute Lymphoblastic Leukemia. Int J Mol Sci 2021, 22(4). https://doi.org/10.3390/ijms22042150

5. Terwilliger T, Abdul-Hay M: Acute lymphoblastic leukemia: a comprehensive review and 2017 update. Blood Cancer J 2017, 7(6):e577. https://doi.org/10.1038/bcj. 2017.53

6. Khazal S, Kebriaei P: Debate: Transplant Is Still Necessary in the Era of Targeted Cellular Therapy for Acute Lymphoblastic Leukemia. Clin Lymphoma Myeloma Leuk 2020, 20(11):713-719. https://doi.org/10.1016/j.clml.2020.06.011

7. Locatelli F, Schrappe M, Bernardo ME, Rutella S: How I treat relapsed childhood acute lymphoblastic leukemia. Blood 2012, 120(14):2807-2816. https://doi.org/10.1182/blood-2012-02-265884

8. Ko RH, Ji L, Barnette P, Bostrom B, Hutchinson R, Raetz E, Seibel NL, Twist CJ, Eckroth E, Sposto R et al: Outcome of patients treated for relapsed or refractory acute lymphoblastic leukemia: a Therapeutic Advances in Childhood Leukemia Consortium study. J Clin Oncol 2010, 28(4):648-654. https://doi.org/10.1200/JC0.2009.22.2950

9. Gu R, Liu F, Zou D, Xu Y, Lu Y, Liu B, Liu W, Chen X, Liu K, Guo Y et al: Efficacy and safety of CD19 CAR T constructed with a new anti-CD19 chimeric antigen receptor in relapsed or refractory acute lymphoblastic leukemia. J Hematol Oncol 2020, 13(1):122. https://doi.org/10.1186/s13045-020-00953-8

10. Bouziana S, Bouzianas D: Exploring the Dilemma of Allogeneic Hematopoietic Cell Transplantation after Chimeric Antigen Receptor T Cell Therapy: To Transplant or Not? Biol Blood Marrow Transplant 2020, 26(8):e183-e191. https://doi.org/10.1016/j.bbmt.2020.04.003

11. Jiang $\mathrm{H}, \mathrm{Hu} \mathrm{Y}, \mathrm{Mei} \mathrm{H}$ : Consolidative allogeneic hematopoietic stem cell transplantation after chimeric antigen receptor T-cell therapy for relapsed/refractory B-cell acute lymphoblastic leukemia: who? When? Why? Biomark Res 2020, 8(1):66. https://doi.org/10.1186/s40364-020-00247-8

12. Greenbaum U, Mahadeo KM, Kebriaei P, Shpall EJ, Saini NY: Chimeric Antigen Receptor T-Cells in B-Acute Lymphoblastic Leukemia: State of the Art and Future Directions. Front Oncol 2020, 10:1594. https://doi.org/10.3389/fonc.2020.01594

13. An F, Wang H, Liu Z, Wu F, Zhang J, Tao Q, Li Y, Shen Y, Ruan Y, Zhang Q et al: Influence of patient characteristics on chimeric antigen receptor T cell therapy in B-cell acute lymphoblastic leukemia. Nat Commun 2020, 11(1):5928. https://doi.org/10.1038/s41467-020-19774-X 
14. K AREM S LIM , E MILE N INI ,D AMIEN F ORESTIER , F ABRICE K WIATKOWSKI , J ACQUES C HIPPONI,Y VES P ANIS :METHODOLOGICAL INDEX FOR NON-RANDOMIZED STUDIES ( MINORS ): DEVELOPMENT AND VALIDATION OF A NEW INSTRUMENT.ANZ J.SUrg. 2003;73:712-716.

https://doi.org/10.1046/j.1445-2197.2003.02748.x

15. Zhao H, Wei J, Wei G, Luo Y, Shi J, Cui Q, Zhao M, Liang A, Zhang Q, Yang J et al: Pre-transplant MRD negativity predicts favorable outcomes of CAR-T therapy followed by haploidentical HSCT for relapsed/refractory acute lymphoblastic leukemia: a multi-center retrospective study. $J$ Hematol Oncol 2020, 13(1):42. https://doi.org/10.1186/s13045-020-00873-7

16. Zhang X, Lu XA, Yang J, Zhang G, Li J, Song L, Su Y, Shi Y, Zhang M, He J et al: Efficacy and safety of anti-CD19 CAR T-cell therapy in 110 patients with B-cell acute lymphoblastic leukemia with high-risk features. Blood Adv 2020, 4(10):2325-2338. https://doi.org/10.1182/bloodadvances.2020001466.

17. Wang J, Mou N, Yang Z, Li Q, Jiang Y, Meng J, Liu X, Deng Q: Efficacy and safety of humanized anti-CD19-CAR-T therapy following intensive lymphodepleting chemotherapy for refractory/relapsed B acute lymphoblastic leukaemia. Br J Haemato/ 2020, 191(2):212-222.https://doi.org/

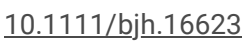

18. Tu S, Huang R, Guo Z, Deng L, Song C, Zhou X, Yue C, Zhang L, He Y, Yang J et al: Shortening the ex vivo culture of CD19-specific CAR T-cells retains potent efficacy against acute lymphoblastic leukemia without CAR T-cell-related encephalopathy syndrome or severe cytokine release syndrome. Am $J$ Hematol 2019, 94(12):E322-E325.https://doi.org/10.1002/ajh.25630

19. Park JH, Riviere I, Gonen M, Wang X, Senechal B, Curran KJ, Sauter C, Wang Y, Santomasso B, Mead E et al: Long-Term Follow-up of CD19 CAR Therapy in Acute Lymphoblastic Leukemia. N Engl J Med 2018, 378(5):449-459.https://doi.org/10.1056/NEJMoa1709919

20. Pan J, Yang JF, Deng BP, Zhao XJ, Zhang X, Lin YH, Wu YN, Deng ZL, Zhang YL, Liu SH et al: High efficacy and safety of low-dose CD19-directed CAR-T cell therapy in 51 refractory or relapsed B acute lymphoblastic leukemia patients. Leukemia 2017, 31(12):2587-2593.https://doi.org L 10.1038/leu.2017.145

21. Ma Y, Zhang S, Fang H, Yu K, Jiang S: A phase I study of CAR-T bridging HSCT in patients with acute CD19(+) relapse/refractory B-cell leukemia. Oncol Lett 2020, 20(4):20.https://doi.org/10.3892/ol.2020.11881

22. Jiang H, Li C, Yin P, Guo T, Liu L, Xia L, Wu Y, Zhou F, Ai L, Shi W et al: Anti-CD19 chimeric antigen receptor-modified T-cell therapy bridging to allogeneic hematopoietic stem cell transplantation for relapsed/refractory B-cell acute lymphoblastic leukemia: An open-label pragmatic clinical trial. American Journal of Hematology 2019, 94(10):1113-1122. https://doi.org/ 10.1002/ajh.25582

23. Hay KA, Gauthier J, Hirayama AV, Voutsinas JM, Wu Q, Li D, Gooley TA, Cherian S, Chen X, Pender BS et al: Factors associated with durable EFS in adult B-cell ALL patients achieving MRD-negative CR after CD19 CAR T-cell therapy. Blood 2019, 133(15):1652-1663.https://doi.org/ 10.1182/blood-2018-11$\underline{883710}$

24. Gu B, Shi BY, Zhang X, Zhou SY, Chu JH, Wu XJ, Fu CC, Qiu HY, Han Y, Chen SN et al: Allogeneic haematopoietic stem cell transplantation improves outcome of adults with relapsed/refractory Philadelphia chromosome-positive acute lymphoblastic leukemia entering remission following CD19 chimeric antigen receptor T cells. Bone Marrow Transplant 2021, 56(1):91-100. https://doi.org/10.1038/s41409-020-0982-6

25. Finney OC, Brakke HM, Rawlings-Rhea S, Hicks R, Doolittle D, Lopez M, Futrell RB, Orentas RJ, Li D, Gardner RA et al: CD19 CAR T cell product and disease attributes predict leukemia remission durability. J Clin Invest 2019, 129(5):2123-2132. https://doi.org/10.1172/JCl125423

26. Daniel W. Lee, III, MD , Maryalice Stetler-Stevenson, MD PhD , Constance M. Yuan, MD PhD , Nirali N Shah, MD , Cindy Delbrook, RN , Bonnie Yates, RN, PNP , Hua Zhang, PhD , Ling Zhang, PhD , James N. Kochenderfer, MD , Steven A. Rosenberg, MD PhD , Terry J Fry, MD , David Stroncek, MD , Crystal L. Mackall, MD: Long-Term Outcomes Following CD19 CAR T Cell Therapy for B-ALL Are Superior in Patients Receiving a Fludarabine/Cyclophosphamide Preparative Regimen and Post-CAR Hematopoietic Stem Cell Transplantation Blood(2016)128(22): 218. https://doi.org/10.1182/blood.V128.22.218.218

27. Zhimin Zhai, MD:Factors Influencing Efficacy of CD19-CAR-T Cells in Children: Factors Influencing Efficacy of CD19-CAR-T Cells in Children and Adults with Relapsed/Refractory B-Cell Lymphoblastic Leukemia. Blood (2018) 132 (Supplement 1): 2656. https://doi.org/10.1182/blood-2018-99-110539

28. Jae H Park, MD , Isabelle Riviere, PhD , Xiuyan Wang, PhD , Yvette Bernal, MS , Terence Purdon , Elizabeth Halton, RN, MS, ANP , Yongzeng Wang, PhD , Kevin J. Curran, MD , Craig S. Sauter, MD , Michel Sadelain, MD PhD , Renier J. Brentjens, MD PhD : Implications of Minimal Residual Disease Negative Complete Remission (MRD-CR) and Allogeneic Stem Cell Transplant on Safety and Clinical Outcome of CD19-Targeted 19-28z CAR Modified T Cells in Adult Patients with Relapsed, Refractory B-Cell ALL. Blood (2015) 126 (23): 682.https://doi.org/10.1182/blood.V126.23.682.682

29. Noelle V Frey, Pamela A Shaw, Elizabeth O Hexner, Edward Pequignot, Saar Gill, Selina M Luger, James K Mangan, Alison W Loren, Alexander E Perl, Shannon L Maude, Stephan A Grupp, Nirav N Shah, Joan Gilmore, Simon F Lacey, Jos J Melenhorst, Bruce L Levine, Carl H June, David L Porter; Optimizing Chimeric Antigen Receptor T-Cell Therapy for Adults With Acute Lymphoblastic Leukemia. J Clin Oncol. 2020 Feb 10;38(5):415-422. https://doi.org/10. 1200/JC0.19.01892

30. Y X Zuo, Y P Jia, J Wu, J B Wang, A D Lu, L J Dong, L J Chang, L P Zhang: Chimeric antigen receptors T cells for treatment of 48 relapsed or refractory acute lymphoblastic leukemia children: long term follow-up outcomes. Zhonghua Xue Ye Xue Za Zhi. 2019 Apr 14;40(4):270-275. https://doi.org/ 10.3760/cma.j. issn.0253-2727.2019.04.002

31. Brentjens RJ, Davila ML, Riviere I, Park J, Wang X, Cowell LG, Bartido S, Stefanski J, Taylor C, Olszewska M et al: CD19-targeted T cells rapidly induce molecular remissions in adults with chemotherapy-refractory acute lymphoblastic leukemia. Sci Trans/ Med 2013, 5(177):177ra38. https://doi.org/ 10.1126/scitransImed.3005930

32. Hu L, Charwudzi A, Li Q, Zhu W, Tao Q, Xiong S, Zhai Z: Anti-CD19 CAR-T cell therapy bridge to HSCT decreases the relapse rate and improves the longterm survival of R/R B-ALL patients: a systematic review and meta-analysis. Annals of Hematology 2021, 100(4):1003-1012. https://doi.org/ 10.1007/s00277-021-04451-w

33. Fatobene G, Rocha V, St Martin A, et al. Nonmyeloablative Alternative Donor Transplantation for Hodgkin and Non-Hodgkin Lymphoma: From the LWPEBMT, Eurocord, and CIBMTR. J Clin Oncol. 2020; 38(14):1518-1526. https://doi. org/10.1200/JC0.19. 02408

Page 6/15 
34. Hall EM, Yin DE, Goyal RK, Ahmed AA, Mitchell GS, St Peter SD, Flatt TG, Ahmed IA, Li W, Hendrickson RJ et al: Tisagenlecleucel infusion in patients with relapsed/refractory ALL and concurrent serious infection. J Immunother Cancer 2021, 9(1).https://doi. org/10.1136/jitc-2020-001225

35. Maude SL, Frey N, Shaw PA, Aplenc R, Barrett DM, Bunin NJ, Chew A, Gonzalez VE, Zheng Z, Lacey SF et al: Chimeric antigen receptor T cells for sustained remissions in leukemia. N Engl J Med 2014, 371(16):1507-1517. https://doi. org/10.1056/NEJMoa1407222

36. Polosa R, Cacciola RR, Prosperini G, Spicuzza L, Morjaria JB, Di Maria GU: Endothelial-coagulative activation during chronic obstructive pulmonary disease exacerbations. Haematologica 2008, 93(8):1275-1276. https://doi.org/10.3324/haematol.12798

37. Duval M, Klein JP, He W, Cahn JY, Cairo M, Camitta BM, Kamble R, Copelan E, de Lima M, Gupta V et al: Hematopoietic stem-cell transplantation for acute leukemia in relapse or primary induction failure. J Clin Oncol 2010, 28(23):3730-3738. https://doi.org/ 10.1200/JC0.2010.28.8852

38. Berry NK, Scott RJ, Sutton R, Law T, Trahair TN, Dalla-Pozza L, Ritchie P, Barbaric D, Enjeti AK: Enrichment of atypical hyperdiploidy and IKZF1 deletions detected by SNP-microarray in high-risk Australian AIEOP-BFM B-cell acute lymphoblastic leukaemia cohort. Cancer Genet 2020, 242:8-14. https://doi.org/10.1016/j.cancergen.2020.01.051

39. Martin Schrappe, Kirsten Bleckmann, Martin Zimmermann, Andrea Biondi, Anja M"oricke, Franco Locatelli, Gunnar Cario, Carmelo Rizzari, Andishe Attarbaschi, Maria Grazia Valsecchi, Claus R. Bartram, Elena Barisone, Felix Niggli, Charlotte Niemeyer, Anna Maria Testi, Georg Mann, Ottavio Ziino, Beat Sch“afer, Renate PanzerGr"umayer, Rita Beier, Rosanna Parasole, Gudrun G”ohring, Wolf-Dieter Ludwig, Fiorina Casale, Paul-Gerhardt Schlegel, Giuseppe Basso, and Valentino Conter:Reduced-Intensity Delayed Intensification in Standard-Risk_Pediatric Acute Lymphoblastic Leukemia Defined by_Undetectable Minimal Residual Disease_Results of an_International Randomized Trial (AIEOP-BFM ALL 2000).J.Clin Oncol.2018 Jan 20;36(3):244253. https://doi.org/10.1200/JC0.2017. 74.4946

40. Shadman M, Gauthier J, Hay KA, Voutsinas JM, Milano F, Li A, Hirayama AV, Sorror ML, Cherian S, Chen X et al: Safety of allogeneic hematopoietic cell transplant in adults after CD19-targeted CAR T-cell therapy. Blood Adv 2019, 3(20):3062-3069. https://doi.org/10.1182/ bloodadvances.2019000593.

41. Fabrizio VA, Kernan NA, Boulad F, Cancio M, Allen J, Higman M, Margossian SP, Mauguen A, Prockop S, Scaradavou A et al: Low toxicity and favorable overall survival in relapsed/refractory B-ALL following CAR T cells and CD34-selected T-cell depleted allogeneic hematopoietic cell transplant. Bone Marrow Transplant 2020, 55(11):2160-2169.https:// doi.org/10.1038/s41409-020-0926-1

\section{Tables}

Table 1区Characteristics of included studies 


\begin{tabular}{|c|c|c|c|c|c|c|c|c|c|c|}
\hline Study & Year & $\begin{array}{l}\text { No.of } \\
\text { Patients(HSCT/non- } \\
\text { HSCT) }\end{array}$ & $\begin{array}{l}\text { Mean } \\
\text { age(years) }\end{array}$ & Ethnicity & $\begin{array}{l}\text { Costimulatory } \\
\text { domain }\end{array}$ & $\begin{array}{l}\text { Mid } \\
\text { days } \\
\text { between } \\
\text { CART } \\
\text { and } \\
\text { HSCT }\end{array}$ & $\begin{array}{l}\text { Prior } \\
\text { HSCT(\%*) }\end{array}$ & $\begin{array}{l}\text { BCR- } \\
\text { ABL1/ph+ } \\
\left(\%^{*}\right)\end{array}$ & Outcome & MINOR \\
\hline Bin Gu[24] & 2020 & $51(30 / 21)$ & 34 & Asian & $4-1 \mathrm{BB}$ & $46 d$ & 0 & $100 \%$ & OS,LFS & 24 \\
\hline $\begin{array}{l}\text { Jia } \\
\text { Wang[17] }\end{array}$ & 2020 & $20(5 / 15)$ & 42 & Asian & $4-1 \mathrm{BB}$ & NR & $21.70 \%$ & $35 \%$ & $\begin{array}{l}\text { OS LFS } \\
\text { RR }\end{array}$ & 23 \\
\hline $\begin{array}{l}\text { Houli } \\
\text { Zhao[15] }\end{array}$ & 2020 & $122(55 / 67)$ & 27 & Asian & $4-1 \mathrm{BB}$ & $66.9 d$ & $\begin{array}{l}\text { inter- } \\
\text { group } \\
\text { difference }\end{array}$ & $18 \%$ & OS,LFS & 24 \\
\hline $\begin{array}{l}\text { YONGYONG } \\
\text { MA[21] }\end{array}$ & 2020 & $9(5 / 4)$ & 34 & Asian & $4-1 \mathrm{BB}$ & $104 d$ & NR & $22.20 \%$ & os & 21 \\
\hline $\begin{array}{l}\text { Xian } \\
\text { Zhang[16] }\end{array}$ & 2020 & $102(75 / 27)$ & 12 & Asian & $4-1 B B+C D 28$ & $63 d$ & $14.50 \%$ & $13.70 \%$ & OS,LFS,RR & 22 \\
\hline $\begin{array}{l}\text { Noelle V. } \\
\text { Frey[29] }\end{array}$ & 2019 & $24(9 / 15)$ & 35 & Caucasian & $4-1 B B$ & $78 d$ & NR & $9 \%$ & OS,LFS & 21 \\
\hline $\begin{array}{l}\text { Huiwen } \\
\text { Jiang, } \\
\text { Ph.D[22] }\end{array}$ & 2019 & $47 \rrbracket 21 / 26 \rrbracket$ & 30 & Asian & NR & $44 d$ & $5.20 \%$ & $10.34 \%$ & OS,LFS & 22 \\
\hline $\begin{array}{l}\text { Kevin A. } \\
\text { Hay[23] }\end{array}$ & 2019 & $45(18 / 27)$ & 45 & Caucasian & $4-1 \mathrm{BB}$ & $70 d$ & $40 \%$ & $20 \%$ & os & 21 \\
\hline Tu[18] & 2019 & $22(8 / 14)$ & 36 & Asian & CD28 & $45 d$ & $24 \%$ & $36 \%$ & OS,RR & 22 \\
\hline Zuo[30] & 2019 & $37(25 / 12)$ & 8 & Asian & CD28 & NR & $6.25 \%$ & $2.10 \%$ & OS,LFS,RR & 23 \\
\hline $\begin{array}{l}\text { Jae H. Park, } \\
\text { M.D[19] }\end{array}$ & 2018 & $43(17 / 26)$ & 44 & Caucasian & CD28 & $74 d$ & $36.00 \%$ & $30.20 \%$ & OS,LFS,RR & 23 \\
\hline $\begin{array}{l}\text { Zhimin } \\
\text { Zhai[27] }\end{array}$ & 2018 & $25(4 / 21)$ & NR & Asian & $4-1 \mathrm{BB}$ & NR & NR & NR & $\mathrm{RR}$ & 21 \\
\hline $\begin{array}{l}\text { Olivia C. } \\
\text { Finney[25] }\end{array}$ & 2018 & $38(13 / 25)$ & NR & Caucasian & 4-1BB & NR & NR & NR & $\mathrm{RR}$ & 23 \\
\hline J Pan[20] & 2017 & $41(23 / 18)$ & 11 & Asian & 4-1BB & $84 d$ & $38.20 \%$ & NR & $\mathrm{RR}$ & 23 \\
\hline $\begin{array}{l}\text { DW Lee } \\
\text { III[26] }\end{array}$ & 2016 & $28(21 / 7)$ & 54 & Caucasian & CD28 & $54 d$ & NR & $9.40 \%$ & $\mathrm{RR}$ & 19 \\
\hline $\begin{array}{l}\text { Jae H } \\
\text { Park[28] }\end{array}$ & 2015 & $36(12 / 24)$ & 45 & Caucasian & CD28 & NR & $39 \%$ & $32 \%$ & os & 21 \\
\hline
\end{tabular}

Abbreviations. OS: overall survival, LFS:leukemia-free survival, RR: relapse rate, NR: not reported

*: the proportion of enrolled patients with a HSCT history or BCR-ABL/ph+

\section{Figures}




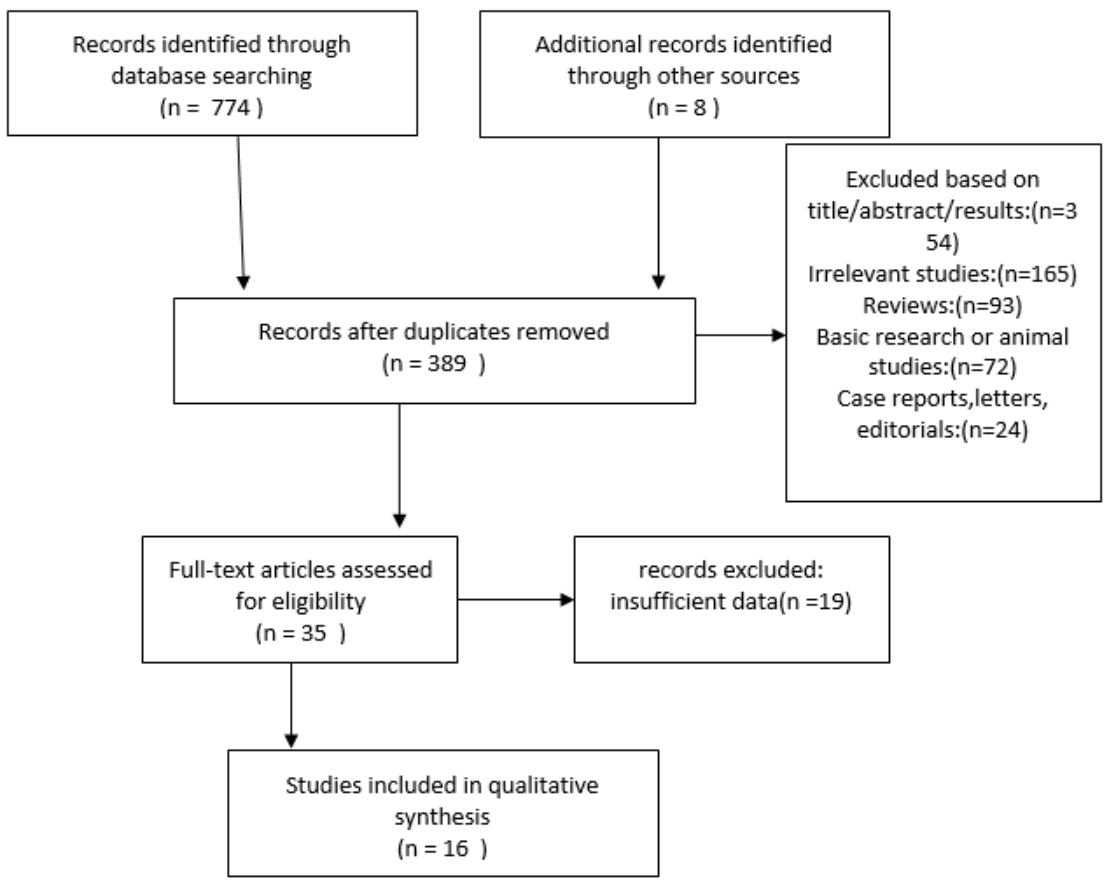

Figure 1

Flow diagram of selecting eligible studies

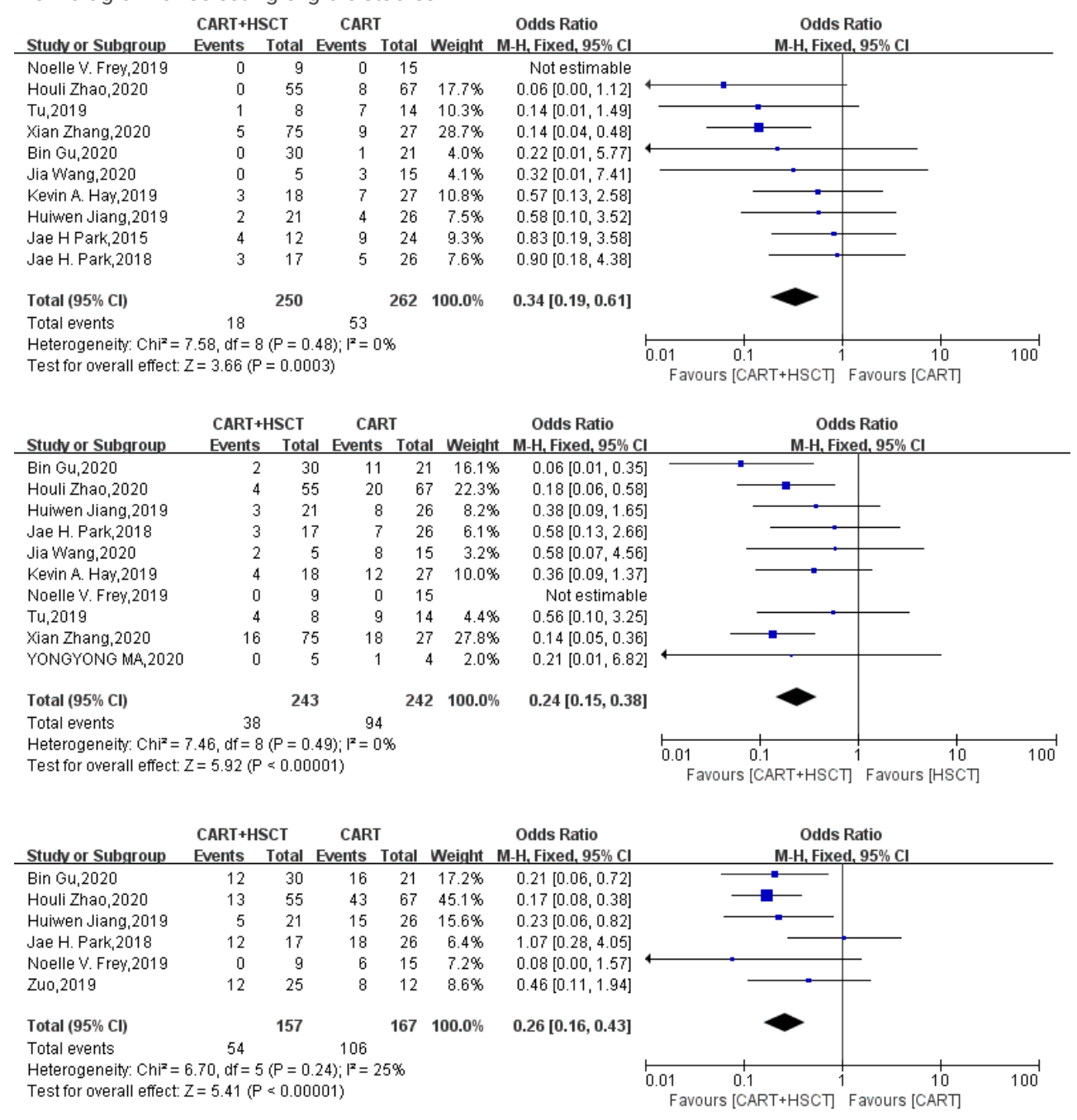

Figure 2 
Forest plot of association between allo-HSCT after CAR-T cell therapy and OS (a)6 month OS (b)1 year OS (c)2 year OS

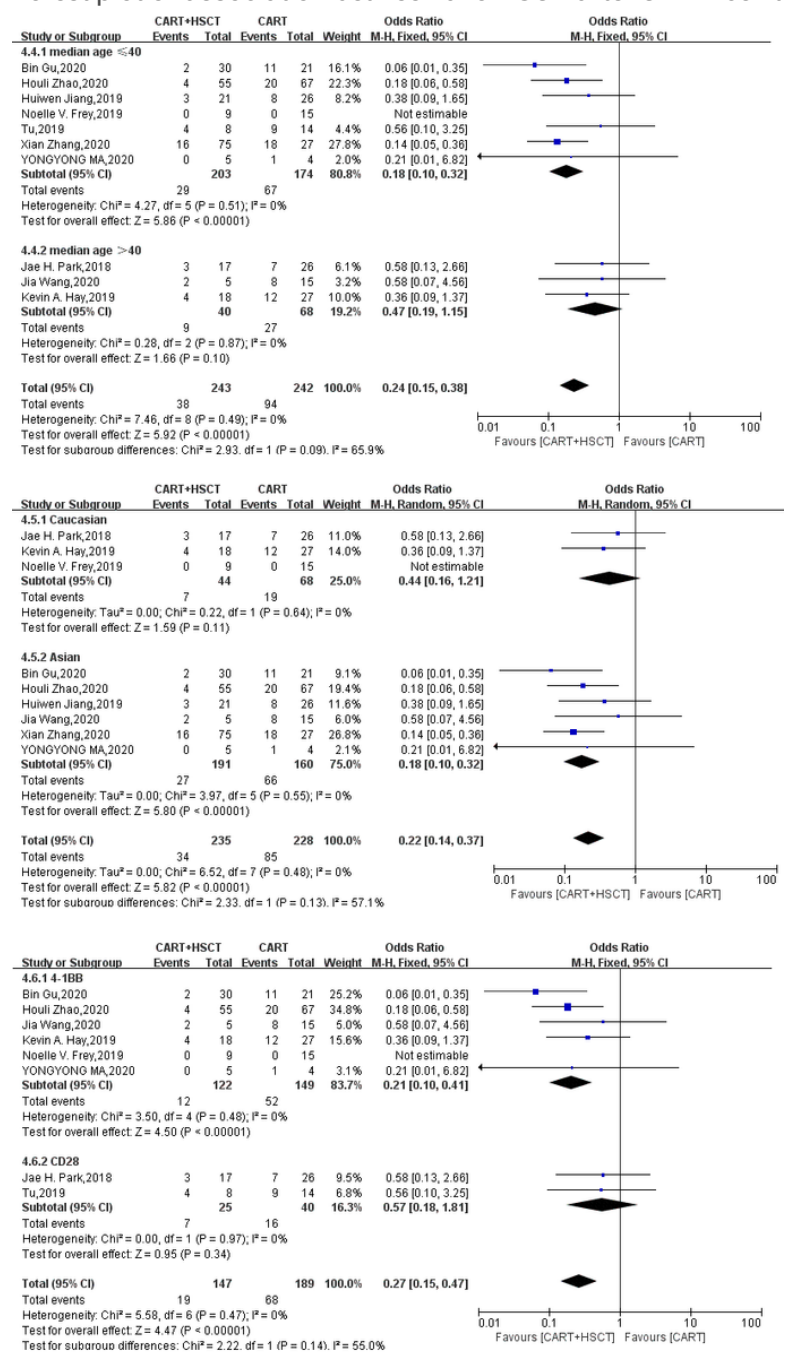

\section{Figure 3}

Subgroup analyses of the relationship between allo-HSCT after CAR-T cell therapy and 1 year OS (a) classified by age (b) classified by ethnicity (c) classified by costimulatory domain 


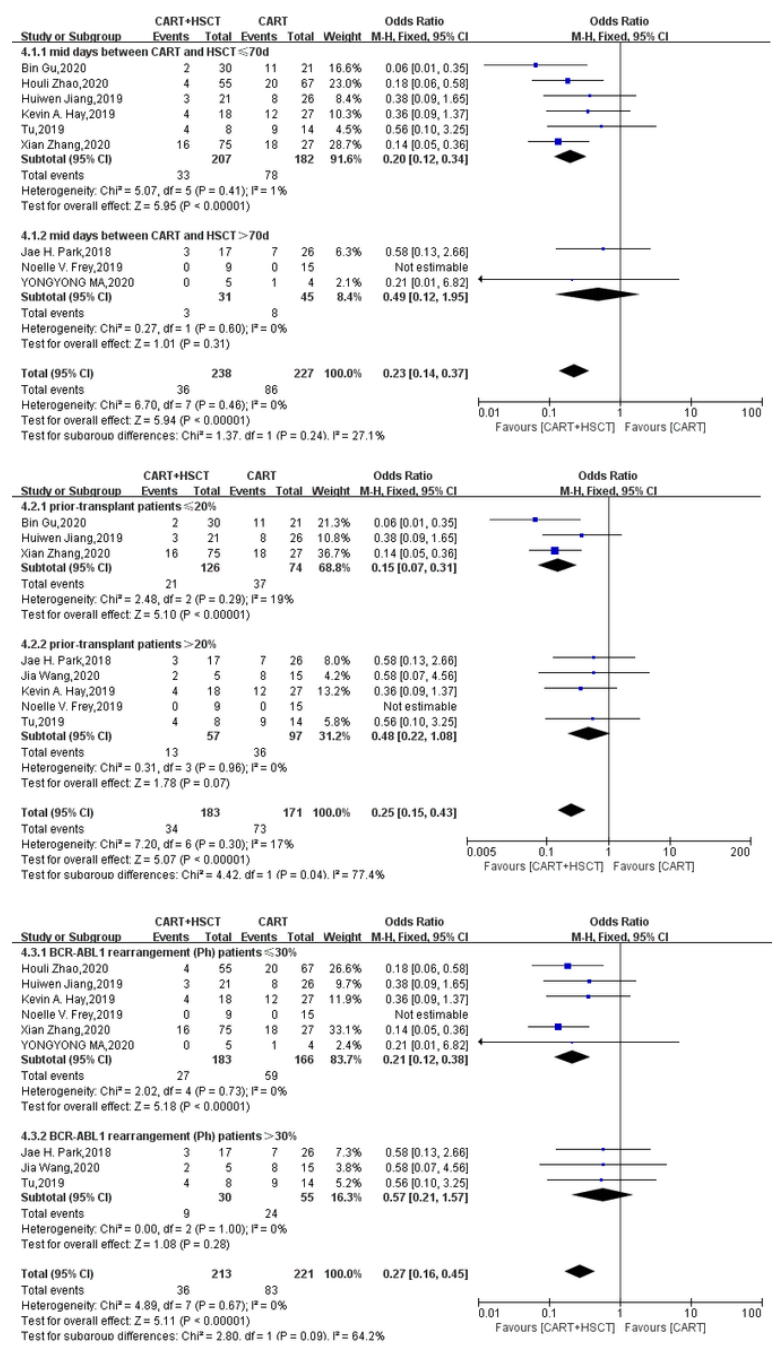

\section{Figure 4}

Intensive subgroup analyses of the relationship between allo-HSCT after CAR-T cell therapy and 1 year OS (a) classified by period between CAR-T cell therapy and allo-HSCT (b) classified by proportion of patients with a HSCT history (c) classified by proportion of BCR-ABL1 rearrangement (Ph) patients 


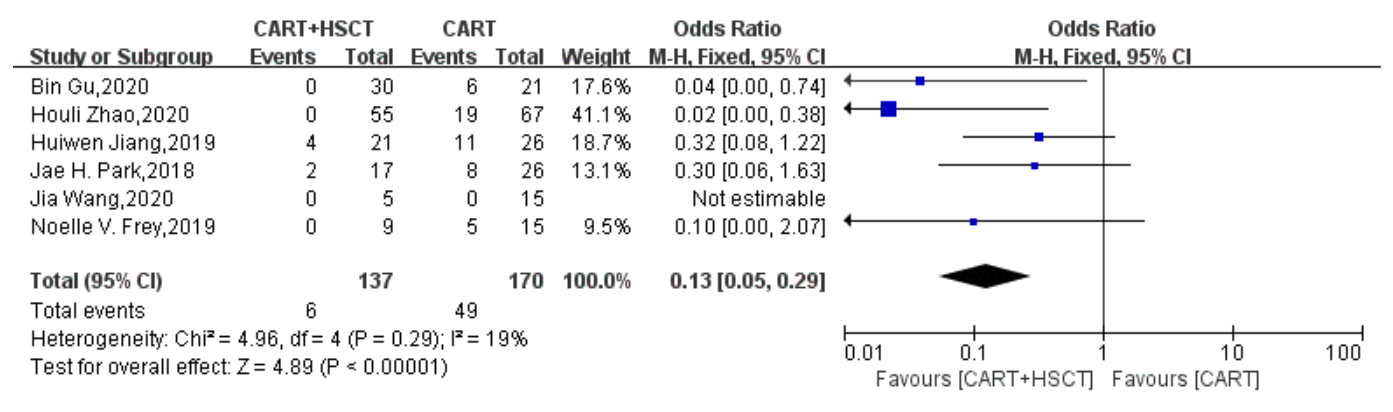

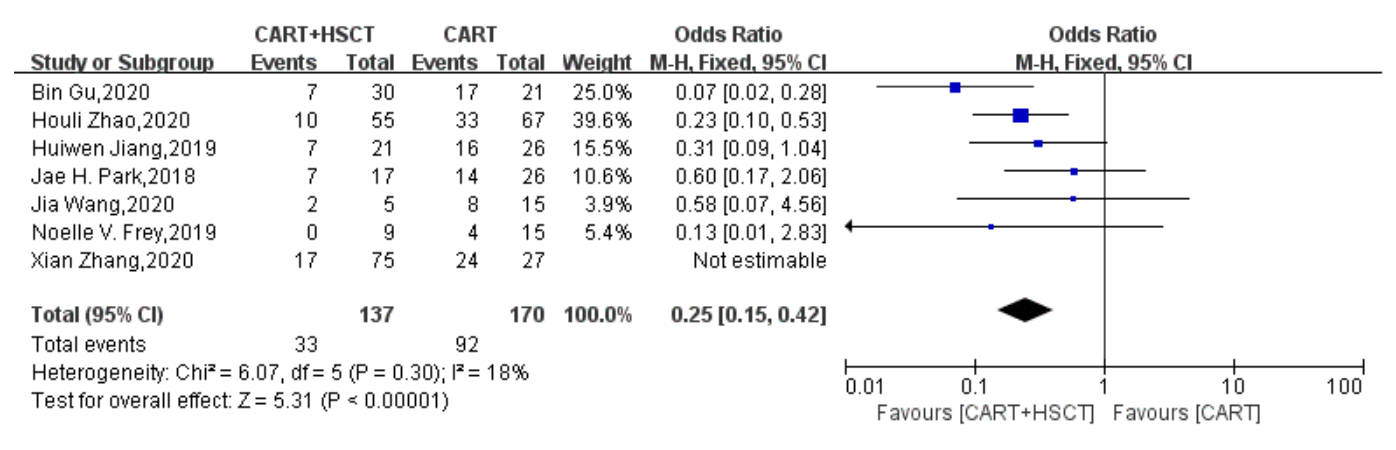

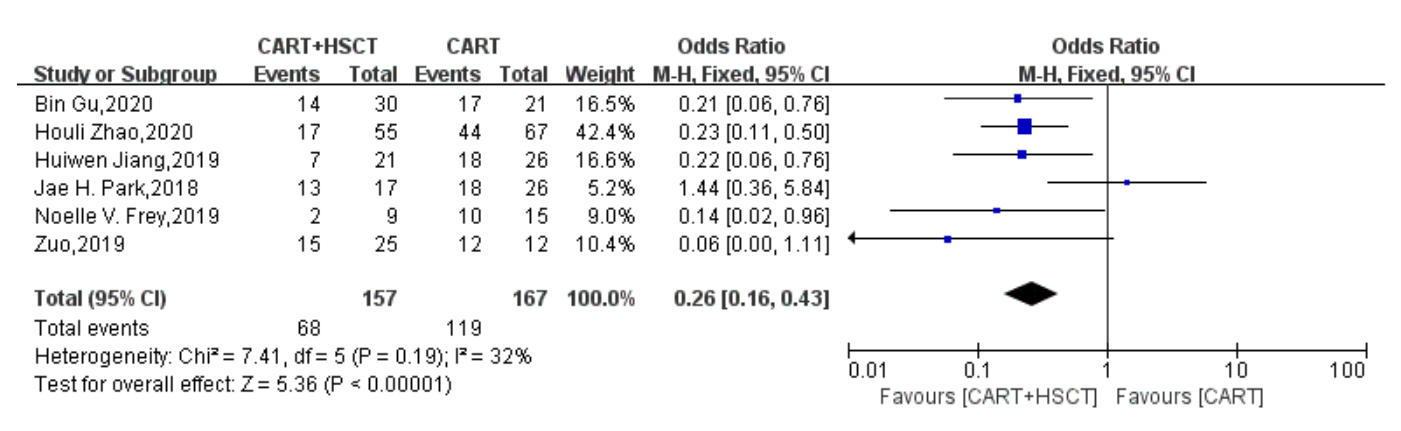

\section{Figure 5}

Forest plot of association between HSCT after CAR-T cell therapy and LFS (a)6 month LFS (b) 1 year LFS (c)2 year LFS 


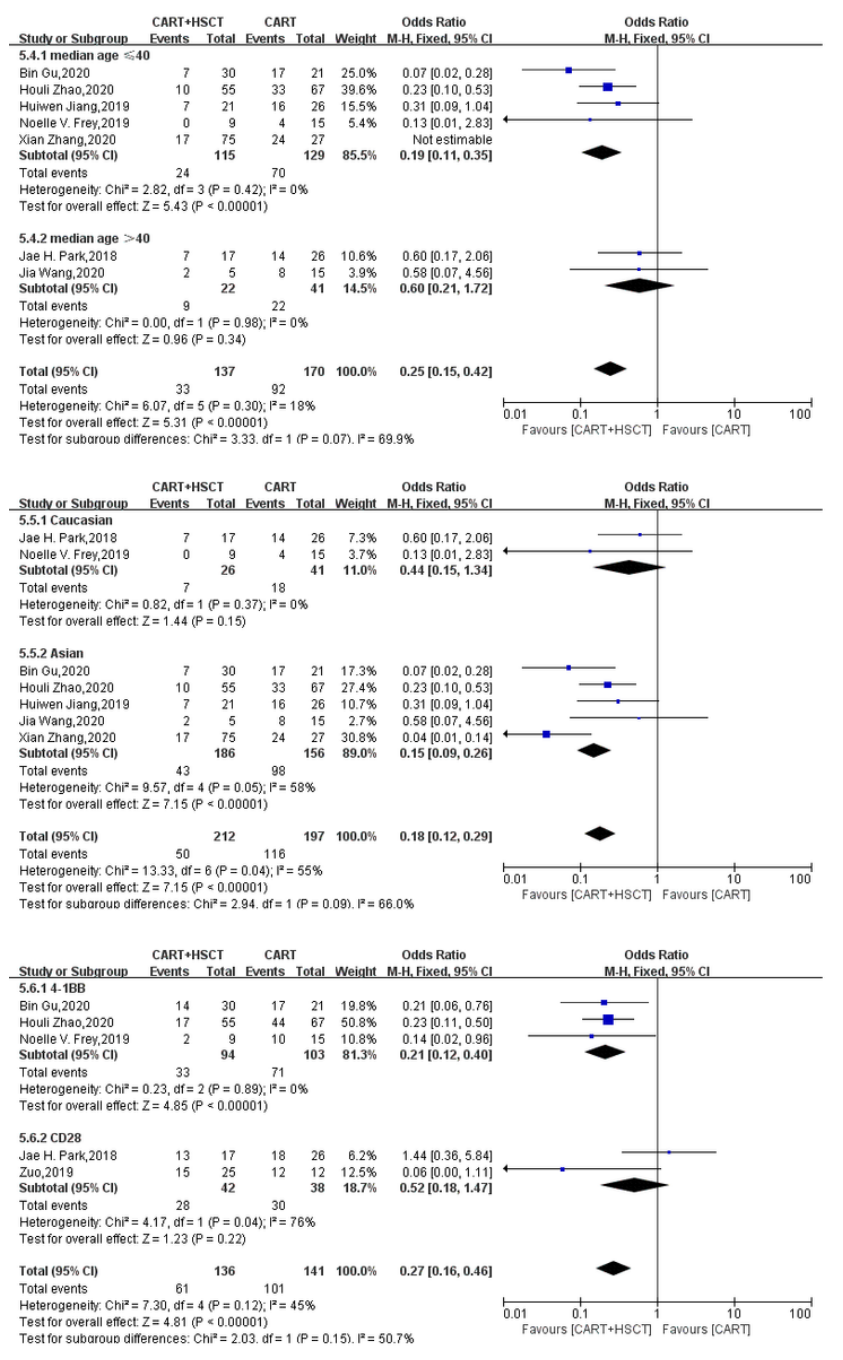

\section{Figure 6}

Subgroup analyses of the relationship between HSCT after CAR-T cell therapy and 1 year LFS (a) classified by age (b) classified by ethnicity (c) classified by costimulatory domain(2 year LFS) 


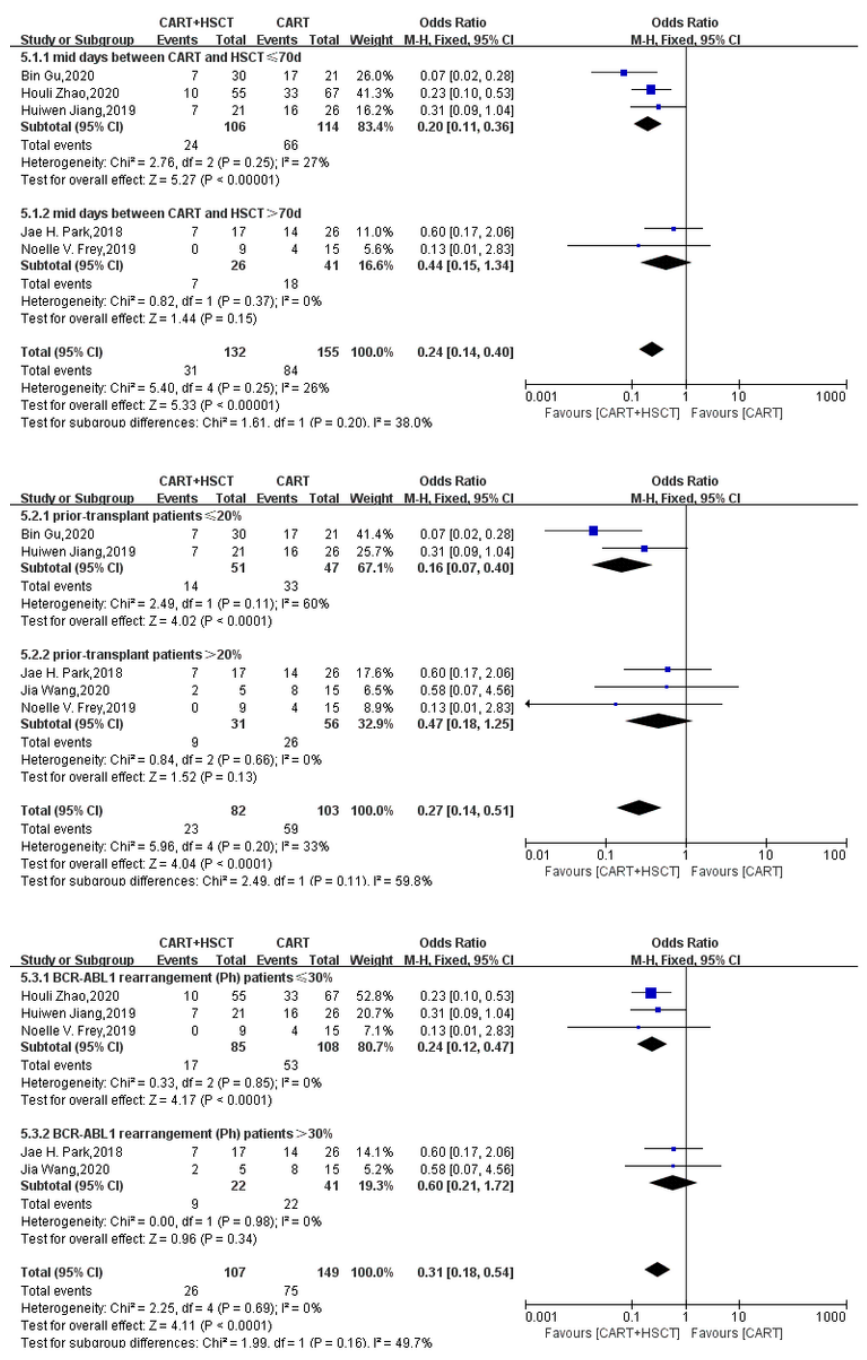

Figure 7

Intensive subgroup analyses of the relationship between HSCT after CAR-T cell therapy and 1 year LFS (a) classified by period between CAR-T cell therapy and allo-HSCT (b) classified by proportion of patients with a HSCT history (c) classified by proportion of BCR-ABL1 rearrangement (Ph) patients

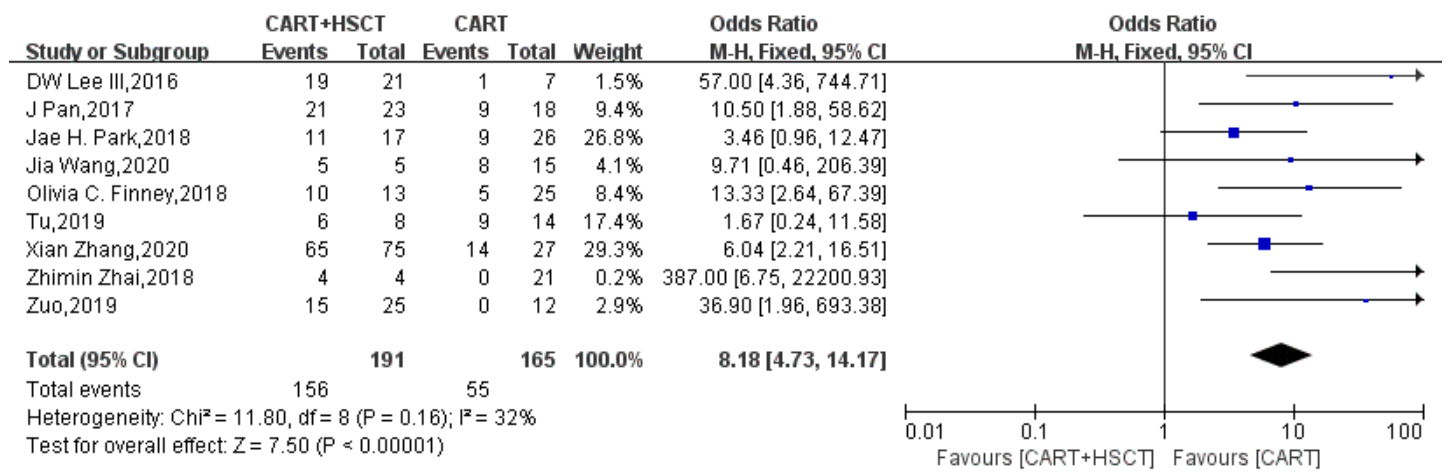

\section{Figure 8}

Forest plot of association between allo-HSCT after CAR-T cell therapy and RR 

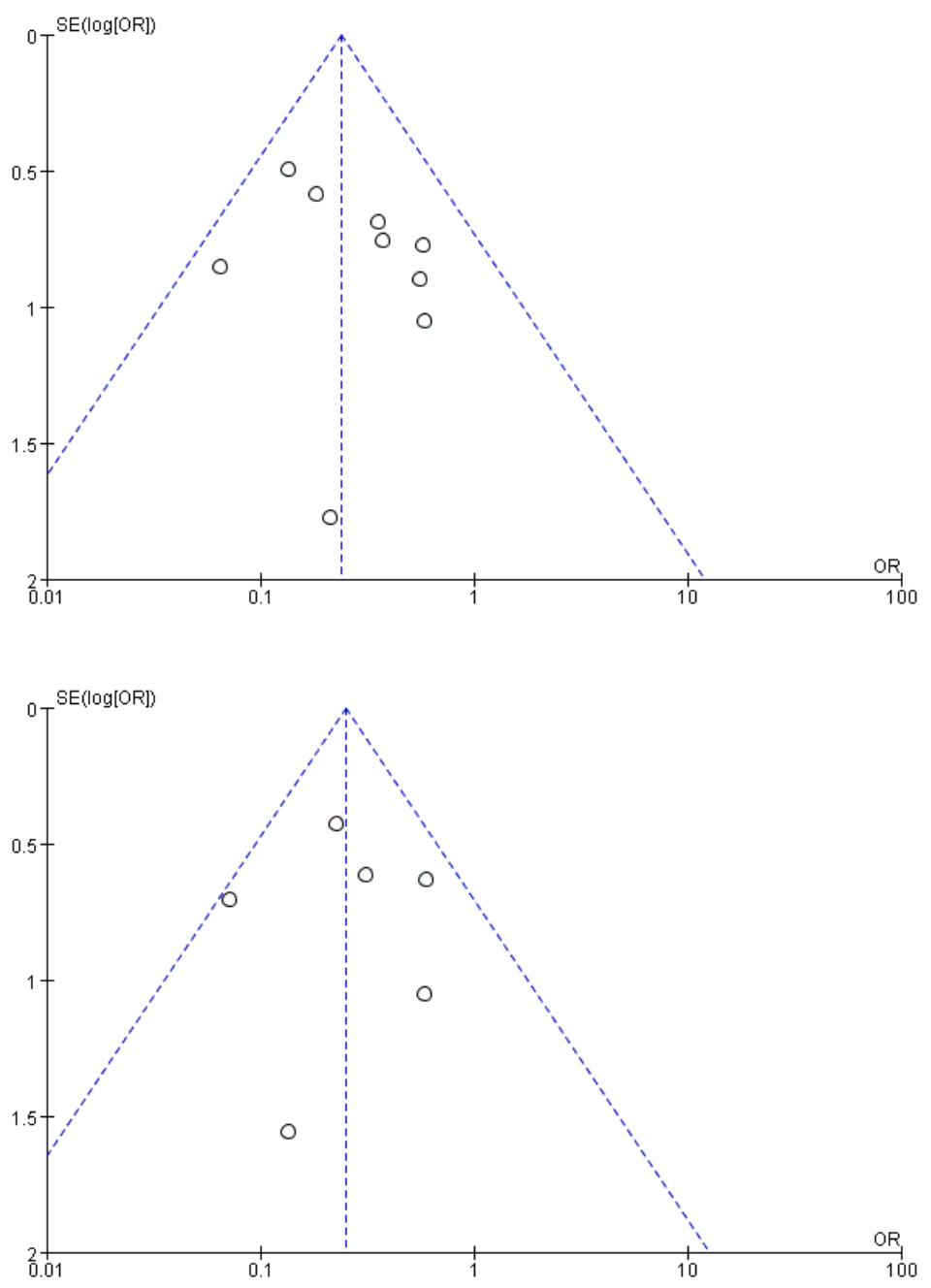

Figure 9

Funnel plot of OS and LFS (a) OS (b)LFS

\section{Supplementary Files}

This is a list of supplementary files associated with this preprint. Click to download.

- tableS1.docx

- tables2.docx 